\title{
CONTINUED SUPPRESSION OF PITUITARY LUTEOTROPHIC ACTIVITY AND FERTILITY IN THE FEMALE MOUSE
}

\author{
H. M. BRUCE \\ Division of Experimental Biology, National Institute for Medical Research, Mill Hill, \\ London, N.W.7
}

(Received 23rd March 1962)

\begin{abstract}
Summary. Repeated suppression of luteotrophic activity by olfactory stimulation from males other than the stud male, was without effect on the subsequent fertility of female mice at least up to 5 months, the longest period recorded.

Females in which such suppression had occurred, however, showed a tendency towards spontaneous pseudopregnancies following the block, in place of the normal 4-day oestrous cycle. This suggests that such olfactory stimulation may affect the release of luteotrophin rather than its production.

The reaction of the recently-mated female to each period of exposure to alien males was apparently not affected by her reaction to the same situation on previous occasions.
\end{abstract}

\section{INTRODUCTION}

The block to pregnancy in the mouse caused by exposing the newly-mated female to the proximity of males other than the stud male (Bruce, 1959) is essentially a failure of implantation due to suppression of the luteotrophic activity of the adenohypophysis normally initiated by mating (Bruce \& Parkes, 1960). The primary stimulus appears to be olfactory because recently-mated anosmic female mice, from which the olfactory lobes have been removed, virtually fail to respond to the presence of males (Bruce \& Parrott, 1960). Moreover, under suitable conditions, the block to pregnancy can be induced merely by housing the female in a box recently vacated by male mice (Parkes $\&$ Bruce, 1962). The block to pregnancy is thus neurohumoral in nature, and whatever the intermediate pathways, the adenohypophysis is deeply involved at the hormonal end of the reaction.

Successive potential pregnancies in the same female can be blocked by repeated exposure to males. Implantation can be prevented in successive pregnancies, and the possible long-term effect of such continued inhibition of luteotrophic activity is clearly of interest. Female mice were therefore reexposed to males after successive matings and maintained under observation for as long as pregnancies continued to fail. 


\section{TEGHNIQUE}

The design of the main experiment was as follows: seventy-six females, in which a first pregnancy had been blocked by exposure to males of a different strain from the stud male, were returned to the stud males and examined daily for mating. After the second mating they were again exposed to the alien males, and if the second pregnancy was also blocked they were returned once more to the stud males, and so on. In this way mating took place consistently at every alternate oestrus, the intervening oestrus indicating that the pregnancy which should have followed the previous mating had been blocked. Most of the females were re-introduced to the stud male as soon as the block to the first pregnancy became manifest, but a few had an interval of several weeks after the first block. About one-third were always returned to the same stud male and exposed to the same group of males after each mating. The others were deliberately paired with a different stud male for each mating and subsequently exposed to groups of males other than those experienced previously. These minor variations in treatment had no influence on the females' behaviour and they have therefore been disregarded in tabulating the results. Tests were continued until a pregnancy was maintained in spite of exposure to males. At intervals, some females were withdrawn from the experiment and allowed to have an undisturbed pregnancy after their final mating.

In a small subsidiary experiment, nine females, in which the first pregnancy was maintained under the test conditions, were not allowed to lactate but were returned to the stud males within a few days of parturition. Tests were continued on this group until a pregnancy was blocked.

As an arbitrary distinction, previously adopted (Bruce, 1960), the return of oestrus within 7 days of the stud mating was considered as evidence of a blocked pregnancy; a longer interval, in the absence of pregnancy, was presumed to indicate pseudopregnancy.

All the stud mice were albino of the randomly-bred $P$ strain used in previous experiments. The males to which the females were exposed belonged to the inbred CBA strain or the G sub-strain of CBA. The females were housed singly throughout the test period.

\section{RESULTS}

\section{REPEATED EXPOSURE AND THE REACTION OF THE FEMALE}

The rate at which consecutive exposures failed to interrupt pregnancy (or pseudopregnancy) is summarized in Table 1. About one-third (twenty-six out of seventy-six) of the females in which the first pregnancy had been blocked, carried the litter from the second mating through the second period of exposure. Approximately the same proportion of those in which pregnancy was again blocked carried their litters through the third (thirteen out of forty-seven) and fourth (eleven out of thirty-two) periods of exposure, respectively. For subsequent exposures, the numbers of females remaining in test became too few for a satisfactory estimate of the proportion of blocked pregnancies to be made. On the other hand, in the subsidiary experiment four of the nine females in 
which the first pregnancy was maintained, failed to maintain the second pregnancy under the test conditions, and three failed to maintain the third pregnancy. One female carried four successive litters before pregnancy was

TABLE 1

EFFEGT OF EXPOSURE TO MALES REPEATED AFTER SUCGESSIVE

MATINGS: FEMALES IN WHICH THE FIRST PREGNANCY WAS BLOCKED

\begin{tabular}{c|c|c|c|c}
\hline & & & \multicolumn{2}{|c}{$\begin{array}{c}\text { Pregnancy (or pseudopregnancy) } \\
\text { maintained }\end{array}$} \\
$\begin{array}{c}\text { Mating } \\
\text { No. }\end{array}$ & $\begin{array}{c}\text { No. females } \\
\text { tested }\end{array}$ & $\begin{array}{c}\text { Pregnancy } \\
\text { blocked }\end{array}$ & No. & Proportion (\%) \\
\hline 1 & 76 & 76 & & \\
2 & 76 & 50 & $23+(3)$ & 34 \\
3 & 47 & 34 & $10+(3)$ & 28 \\
4 & 32 & 21 & 11 & 34 \\
5 & 13 & 11 & 2 & \\
6 & 7 & 7 & 1 & \\
7 & 3 & $2 *$ & 1 & \\
\hline
\end{tabular}

* Both females allowed undisturbed pregnancies after the eighth mating.

blocked by the fifth period of exposure, while the remaining female was regarded as virtually immune to the influence of males in this respect. Observations on this female were discontinued after she had carried six consecutive litters through periods of exposure (Table 2).

TABLE 2

EFFEGT OF EXPOSURE TO MALES REPEATED AFTER SUCGESSIVE MATINGS: FEMALES IN WHICH THE FIRST PREGNANCY WAS MAINTAINED

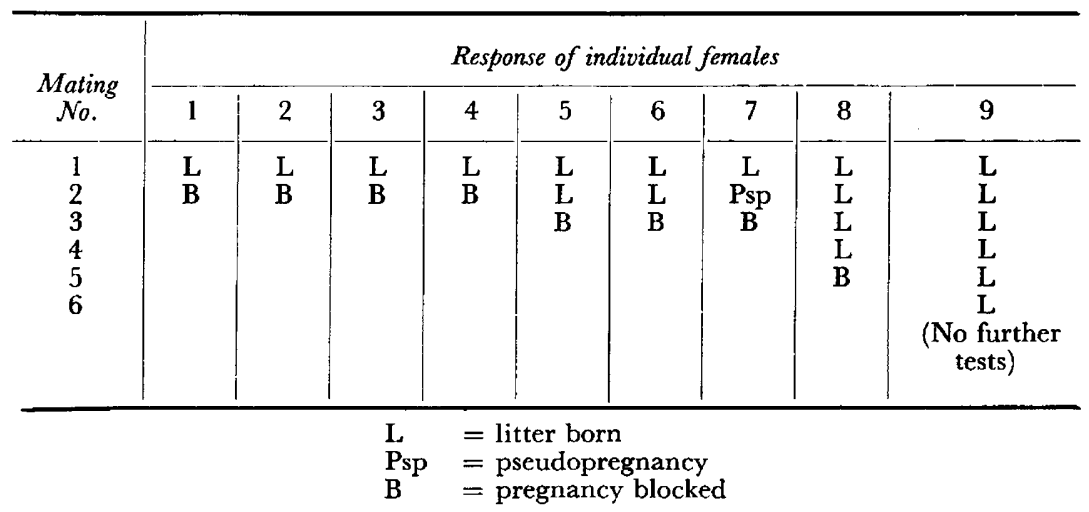

The previous history of the female, therefore, appears to have little influence on her reaction, and in few females could more than four pregnancies be blocked in unbroken succession. Nevertheless, the high blocked-pregnancy rate among females surviving for the fifth to the seventh matings recorded in Table 1 and the resistance shown by the last two females recorded in Table 2, suggests that some selection during the course of the experiment has removed the less sensitive and the more sensitive females, respectively. Individual variation in a 
reaction of this type is to be expected. The surprising thing is that the reaction is so consistent, in spite of the fact that no test situation has, as yet, been devised in which pregnancy will always be blocked in all females.

\section{EFFECT ON FERTILITY OF SUCGESSIVE BLOGKS TO PREGNANCY}

The fertility of females withdrawn from test and left undisturbed after their final mating is illustrated in Text-fig. 1 . All twenty females in which the sequence

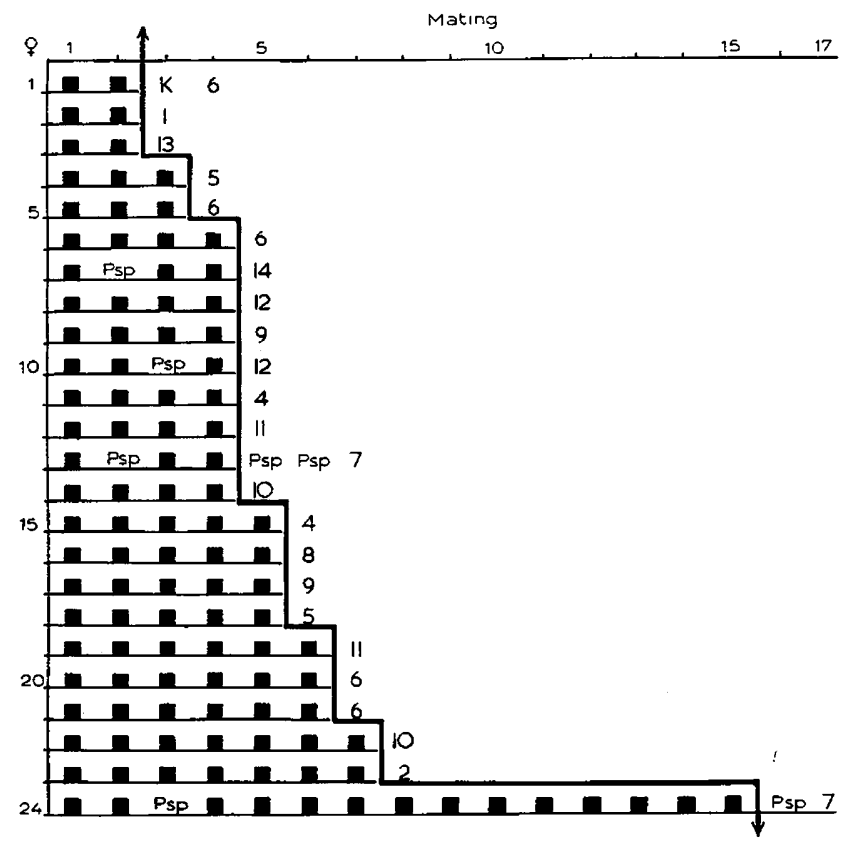

TEXT-FIG. 1. Effect on fertility of successive blocks to pregnancy.
₹ tests stopped; pregnancy undisturbed
Figures = number of young born
$\mathbf{K} \quad=$ litter eaten before count
Psp = pseudopregnancy
$\mathbf{\square} \quad=$ return to oestrus

of blocked pregnancies was uninterrupted, even by pseudopregnancy, immediately became pregnant; 138 young were born. Thus a previous history of blocked pregnancies does not impair the fertility of subsequent undisturbed pregnancies. Of particular interest in this connexion is the behaviour of the last female in the group. A pseudopregnancy was maintained during her third period of exposure, but subsequently she experienced an unbroken sequence of twelve blocked pregnancies before she was withdrawn from test. She became pseudopregnant, although undisturbed, after her sixteenth mating, but a litter was born after the seventeenth mating. By this time the female herself was already about 10 months old. Litters ultimately maintained throughout a period of exposure were normal in all respects. From twenty-five females in which from two to six potential pregnancies had been blocked, a total of 236 young were born.

Out of the seventy-six females in which the first pregnancy was blocked, 
only two failed to become pregnant during the experiment. Both these females became acyclic after four successive pregnancies had been blocked. They were withdrawn from the experiment after several weeks of anoestrus. It is unlikely that any significance can be attached to the behaviour of these two individuals.

EFFECT OF SUGCESSIVE BLOGKS TO PREGNANGY ON THE OESTROUS

\section{GYCLE}

It became apparent that after the return of the stud male mating did not always occur as soon as expected. Daily vaginal smears were therefore examined to discover the reason. This proved to be the occurrence of spontaneous pseudopregnancies in place of the expected 4-day cycles among the females concerned. The possibility of undetected infertile matings, which could explain the pseudopregnancies, was ruled out by withholding the re-introduction of the stud male until pro-oestrus. Over half of the females in which more than one pregnancy was blocked (twenty-nine out of fifty) showed this reaction at one time or another. The overall incidence amounted to 25 to $30 \%$ of all cycles measured (Bruce, 1962). This effect on the oestrous cycle is illustrated in Text-fig. 2, which shows the behaviour of five typical females subjected to
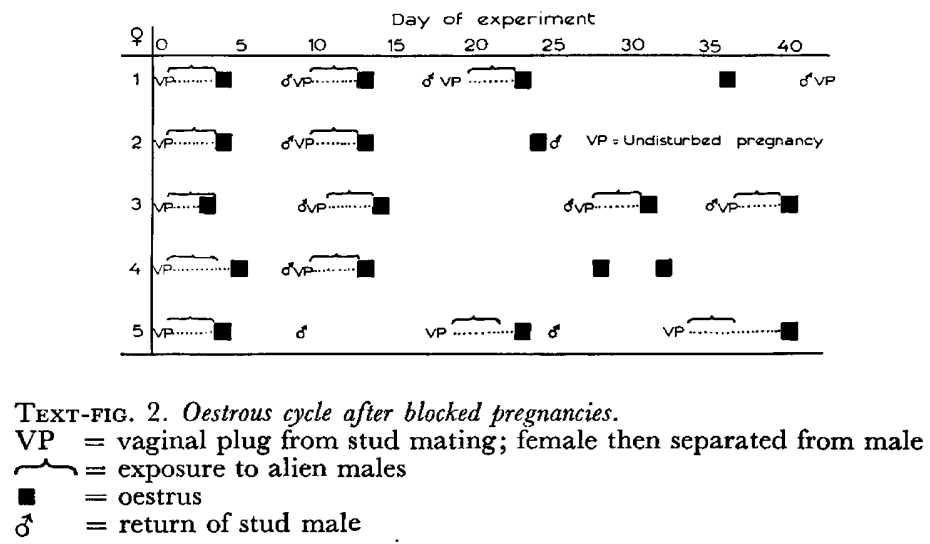

repeated exposures. It is noteworthy that the introduction of the stud male early in such a spontaneous pseudopregnancy (see $\$ 5$ ) did not initiate a new cycle and bring the female rapidly into heat as happens after the introduction of a male to anoestrous females (Whitten, 1956, 1959). Had the Whitten effect occurred under these conditions, the spontaneous pseudopregnancies would have passed undetected.

\section{CONCLUSIONS}

Repeated suppression of pituitary luteotrophic activity by olfactory stimulation, as shown by the failure of the corpora lutea to develop functionally after mating, had no effect at least up to 5 months (the longest continuous period on record) on the subsequent fertility of the female. The previous history of the female appeared to play no part in determining her reaction to such stimulation. Individual variation in sensitivity undoubtedly exists. 
The one unusual feature detected among females submitted to repeated pregnancy-blocks was a tendency towards spontaneous pseudopregnancy following the return of oestrus after a blocked pregnancy. As the females were always paired again with a stud male as soon as possible to permit frequent and regular mating, it is not known whether this tendency persists in subsequent cycles or is restricted to the first cycle after the return of oestrus. Apart from this, the spontaneous pseudopregnancies conformed to no obvious pattern, but general observations nevertheless suggest strongly that they are associated with repeated suppression of luteotrophic activity. Among female mice housed individually the incidence of spontaneous pseudopregnancies is rare (Van der Lee \& Boot, 1955, 1956). In a group of more than 400 females in which the first pregnancy was blocked, twenty-one females, about $5 \%$, had a spontaneous pseudopregnancy after the return of oestrus, while among the fifty females in the experiment reported here, in which more than one pregnancy was blocked, over half (twenty-nine females) showed this disturbance of the oestrous rhythm. This tendency for a spontaneous pseudopregnancy to follow a block may indicate the release of pent-up luteotrophin. It is possible that under the particular conditions pertaining to olfactory stimulation the release rather than the production of luteotrophin is affected.

\section{REFERENCES}

Bruce, H. M. (1959) An exteroceptive block to pregnancy in the mouse. Nature, Lond. 184, 105.

Bruce, H. M. (1960) A block to pregnancy in the mouse caused by proximity of strange males. $\mathcal{J}$. Reprod. Fertil. 1, 96.

Bruce, H. M. (1962) Contribution to Discussion: Proceedings of the Neuroendocrinology Symposium, Miami, Florida. December 1961. (In press.)

Bruce, H. M. \& Parkes, A. S. (1960) Hormonal factors in exteroceptive block to pregnancy in mice. 7. Endocrin. 20, xxix.

Bruce, H. M. \& Parrotr, D. M. V. (1960) Role of olfactory sense in pregnancy block by strange males. Science, 131, 1526.

Parkes, A. S. \& Bruce, H. M. (1962) Pregnancy-block in female mice placed in boxes soiled by males. 7. Reprod. Fertil. 4, 303-308.

VAN DER LEe, S. \& Boot, L. M. (1955) Spontaneous pseudopregnancy in mice. Acta physiol. pharm. néerl. 4, 442 .

VAN DER Lee, S. \& Boot, L. M. (1956) Spontaneous pseudopregnancy in mice. II. Acta physiol. pharm. néerl. 5, 213.

Whitten, W. K. (1956) Modification of the oestrous cycle of the mouse by external stimuli associated with the male. F. Endocrin. 13, 399.

Whitten, W. K. (1959) Occurrence of anoestrus in mice caged in groups. J. Endocrin. 18, 102. 